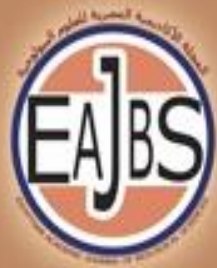

EGYPTIAN ACADEMIC JOURNAL OF
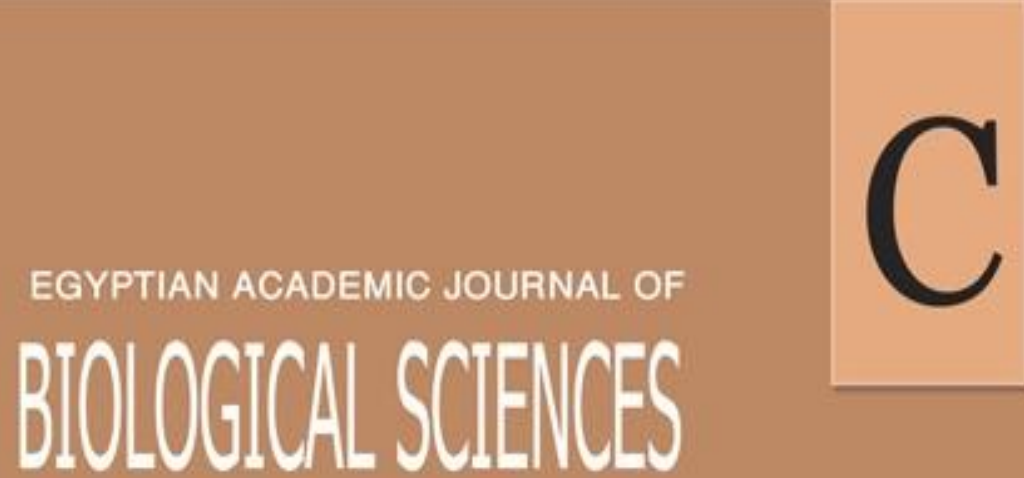

PHYSIOLOGY \& MOLECULARBIOLOGY
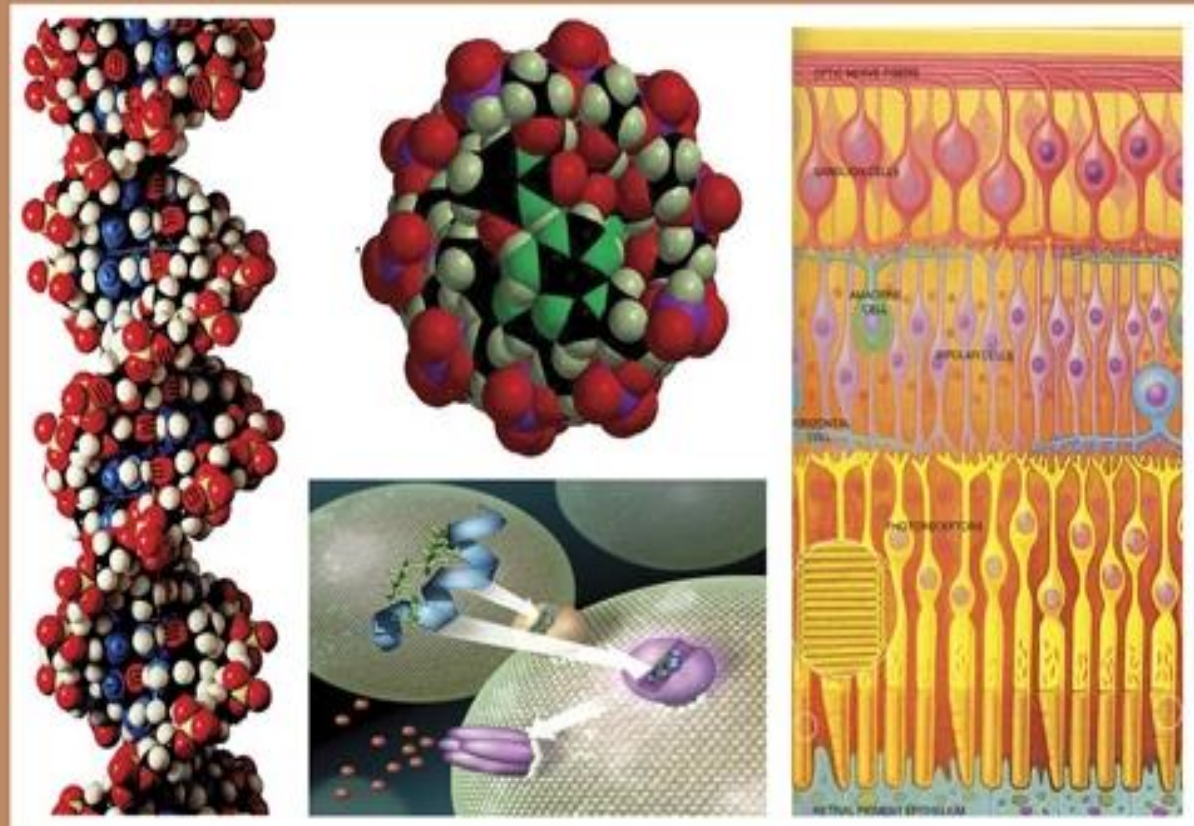

ISSN

2090-0767

WWW.EAJBS.EG.NET

Vol. 13 No. 1 (2021) 
Egypt. Acad. J. Biolog. Sci., 13(1):133-147 (2021)

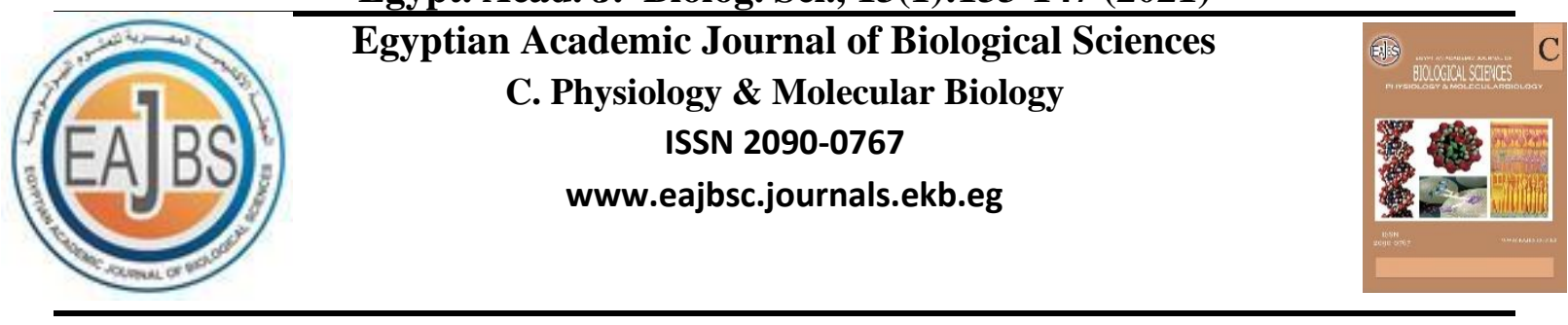

COVID-19: Variable Immune Response in Indian Population

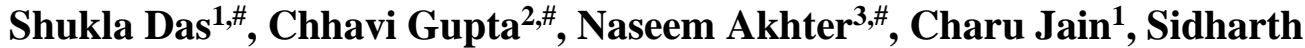
Sonthalia ${ }^{4}$, Saif Ahmad ${ }^{5}$ and Sajad Ahmad Dar ${ }^{1,6, *}$

1-Department of Microbiology, University College of Medical Sciences (University of Delhi) \& GTB Hospital, Delhi, India

2-Northern Railways Central Hospital, Delhi, India

3-Department of Laboratory Medicine, Faculty of Applied Medical Sciences, Albaha University, Albaha, Saudi Arabia

4-Skinnocence: The Skin Clinic \& Research Centre, Gurugram, India

5-Barrow Neurological Institute, Phoenix, Arizona USA

6-Research and Scientific Studies Unit, College of Nursing, Jazan University, Jazan, Saudi Arabia

"These authors contributed equally.

*E. Mail : darsajad990@gmail.com; sdar@jazanu.edu.sa

\section{REVIEW INFO}

Review History

Received:27/3/2021

Accepted:22/5/2021

\section{Keywords:}

COVID-19;

Immune response;

Genetic makeup;

Host gene

polymorphism;

Mortality

\section{ABSTRACT}

With a year and a half into the COVID-19 pandemic, still, variance in terms of transmission and susceptibility of different populations/ethnicities to the disease remains an enigma. The clinical outcome of COVID-19 disease is poor in patients with associated morbidities; however, the reasons behind significant mortality of immuno-competent healthy individuals attributed to fulminant infection remains to be elucidated. Generally, protective B and T cell-mediated immune responses seem to have a tilted balance causing a sustained inflammatory state in SARS-CoV-2 infected individuals. The genetic makeup of an individual is highly likely to play a major role in elicitation as well as the outcome of the immune response in COVID-19 cases. The Indian response to COVID-19 indicates a potential influence of genetic background on host immune response pathways leading to decreased susceptibility and mortality to SARS-CoV-2 infection. Many host genes are involved in the entry and replication of SARS-CoV-2 and the subsequent host immune response. The current review discusses the potential cytokine gene polymorphisms prevalent in the Indian population that may influence the transmission, severity and mortality due to COVID-19 infection.

\section{INTRODUCTION}

In late 2019 or the beginning of the year 2020, a novel virus was discovered later named SARS-CoV-2. The disease caused by this 2019 novel coronavirus (2019$\mathrm{nCoV}$ ) was termed as COVID-19 disease and a pandemic was declared on 11 March 2020 (Wiersinga et al., 2020). There has been the dramatic spread of the virus across the globe owing to droplet/airborne transmission, international travel, high $\mathrm{R}_{0}$ and has significantly affected public health and economies worldwide. 
The cause of the rapid spread of the virus in the community is likely the viral shedding from asymptomatic or presymptomatic individuals; COVID-19 illness can present with varied clinical presentation ranging from asymptomatic carriers to mild to moderate illness to severe respiratory illness, initially thought to be a respiratory virus. Further, as the pandemic progressed, it was observed that it can involve other systems like neurological, cardiovascular etc leading to significant morbidity and mortality and. immune-mediated mechanisms responsible for mortality in COVID-19 pneumonia (Mao et al., 2020).

The disease had led to unprecedented fatal outcomes in the western world; South Asian countries namely India, Afghanistan, Pakistan, Bhutan, Maldives, Bangladesh, Sri Lanka and Nepal were expected to be worst hit by the pandemic owing to dense population and low resource settings but strangely India reported lesser mortality compared to worldwide mortality (Jain et $a l ., 2020)$. There could be various reasons for a better outcome in this part of the world the most important being immune sensitization of populations by various vaccine drives of which most important being BCG vaccines. The majority of the population in South Asian countries has been exposed to BCG vaccine for over half a century and the immunity elicited by BCG vaccine is making people more resistant to COVID-19 morbidity and mortality than in the western world (A.R. Sharma 2020). The hygiene hypothesis may hold special mention due to early exposure to numerous infections, Indian population has well developed immune regulatory system that might have negated severe illness due to COVID-19 (Sehrawat S 2020). Going back to the classical epidemiological triad which states that disease course depends on agent, host and environmental factors, so the genetic background in various populations might be responsible for variable susceptibility to disease and its outcome. We hypothesize the role of prevailing cytokine polymorphism in Indian population as the reason for lower mortality rates due to COVID-19 in this review.

\subsection{COVID-19 Disease: Virology, Pathogenesis:}

SARS-CoV-2 belongs to alpha coronaviruses; these are enveloped, positive-sense, single-stranded RNA viruses; disease in human beings is mainly transmitting through infecting peridomestic animals, which serve as intermediate hosts. The droplet transmission is the main mode of transmission, the later airborne route was also confirmed and the virus is known to exist on the surface for 72 hours (Wiersinga et al., 2020). The structural proteins are encoded by the four structural genes, including spike (S), envelope (E), membrane (M) and nucleocapsid (N) genes. The $\mathrm{S} 2$ subunit of the spike protein of SARS-CoV-2 is highly conserved; SARS-CoV-2 uses ACE2 (angiotensinconverting enzyme 2) cell receptor for entry into the host cell with enhanced binding affinity for ACE2 (Hoffmann M 2020). Transmembrane protease serine 2 (TMPRSS2), an essential serine protease is required for spike glycoprotein priming after binding to ACE2. Following the binding, the $S$ protein binds to the cellular receptor ACE2. Conformation change in $S$ protein facilitates fusion of viral envelope with the cell membrane through the endosomal pathway via clathrin-dependent endocytosis (Hoffmann M 2020). SARSCoV-2 releases RNA into the host cell and is translated into viral polyproteins. The polymerase produces subgenomic mRNAs and is translated into relevant viral proteins. Viral proteins and genome RNA are subsequently assembled into virions in the endoplasmic reticulum and golgi, transported via vesicles and finally released out of the cell. After endocytosis of the viral complex, surface ACE2 is 
down-regulated, resulting in unopposed angiotensin II accumulation. Local activation of the renin-angiotensinaldosterone system may mediate lung injury (Vaduganathan M 2020).

Expression of the ACE2 receptor is found in pulmonary and extrapulmonary tissues including heart, kidney, endothelium and intestine resulting in a plethora of clinical symptoms ranging from asymptomatic presentation to mild flu-like symptoms like fever, sore throat, dry cough, body aches, malaise, diarrhea, conjunctivitis; atypical symptoms like olfactory and gustatory dysfunction or more severe and critical conditions manifesting like myocarditis, myocardial infarction, cerebrovascular complications, acute kidney injury, thrombo-embolic episodes, etc ultimately culminating into multiple organ dysfunction (MODS) (Wiersinga et al., 2020). These complications are more commonly seen in the elderly population and patients with comorbidities like diabetes mellitus, hypertension, chronic lung, kidney, liver, or cardiac diseases, immunosuppressed patients like transplant recipients, malignancies etc.

\subsection{Immune Response to SARS-CoV-2 Infection:}

Following entry of virus via nasal-oral route, viral antigens are recognized by pathogen recognition receptors (PRR) mainly Toll-like receptors 3,7,8 (TLRs) and presented in complex with MHC class I molecules to $\mathrm{T}$ cells leading to activation of helper $\mathrm{CD}^{+}{ }^{+} \mathrm{T}$ cells and cytotoxic $\mathrm{CD}^{+} \mathrm{T}$ cells (Shah et al., 2020). Helper T cells, in turn, activated B cell responses. A well-coordinated network of the immune system, in turn, leads to the secretion of pro-inflammatory cytokines mainly IFN- $\gamma$, TNF- $\alpha$ and IL-6, production of neutralizing antibodies and cytotoxic $\mathrm{T}$ cells helps to clear the virus. The initial release of cytokines and chemokines leads to non-specific activation of mononuclear macrophages that further release excessive pro- inflammatory cytokines in response resulting in a state called hypercytokinemia (also known as cytokine storm). The excessive synthesis of cytokines stimulates the massive proliferation of monocyte-macrophages and induces apoptosis of lymphocytes (Badawi 2020). Indeed, the early stages of COVID-19 are characterized by lymphopenia; lymphocytes progressively decline further during the course of illness.

The pro-inflammatory cytokines drive the recruitment of immune cells including monocytes-macrophages, lymphocytes, and neutrophils at the site of infection, induce pulmonary and vascular injury in lungs and other tissues leading to extensive inflammatory reactions, vascular injury, necrosis, thrombosis, hyaline membrane formation. This immunemediated damage due to hypercytokinemia may culminate into fatal outcomes characterized as ARDS, coagulopathy and multiorgan damage (Badawi 2020; Xu et al., 2020). Simultaneously natural regulatory $\mathrm{T}$ cell (nTreg) and induced regulatory $\mathrm{T}$ cell (iTreg) are directed to infected tissues and via secretion of IL-10 and TGF- $\beta$ inhibit excessive inflammation and repair the tissue. This cytokine milieu decides the outcome of infected patients. The studies have shown that $\mathrm{T}$ cells are over-activated and regulatory $\mathrm{T}$ cells are down-regulated in COVID-19 patients resulting in cytokine storm leading to immune mediated injury and severe disease; further the period of excessive $\mathrm{T}$ cell activation may cause $T$ cell exhaustion and lymphopenia which would result in delayed virus eradication and poor outcomes (Qin et al., 2020).

\section{Indian Scenario:}

India is a densely populated country with a majority of the population living in a close niche owing to limited resources and cultural beliefs and with a high burden of non-communicable diseases like diabetes mellitus etc. With limited health care infrastructure, it was expected at the beginning of the pandemic 
that India will have a very high mortality rate. The first case in India was detected on January 30, a student who returned from Wuhan, the birthplace of SARSCoV-2, later on, more cases were detected. At the end of March 2020, the nationwide lockdown was imposed which led to a delayed peak of COVID-19 in India but slowly whole country came under the effect of the pandemic. As per the latest WHO COVID-19 data on 29 $9^{\text {th }}$ May 2021, more than 27 million cases are reported from India, while the USA has more than 32 million cases and Brazil has more than 16 million cases (Table 1). The feature to be noted is that India has witnessed only 318,895 cumulative deaths which are $1.16 \%$ cumulative deaths of COVID-19 cases; this figure is less compared to Brazil (2.79\%) and USA (1.79\%), absolute numbers being 454,429 for Brazil and
586,890 for USA. Other less populous countries have also reported higher death percentages due to COVID-19 compared to India (WHO 2020). During the early stages of the pandemic, the Indian government came out with the policy of isolating all positive confirmed cases into healthcare facilities with the primary aim to contain the spread of the pandemic and clinically monitor all patients. Subsequently, as the pandemic progressed, it was observed that the majority of the infected population was asymptomatic or have an only mild illness, mortality rates were low so with increasing burden coming on health infrastructure, the policy was changed and home isolation policy was adopted where asymptomatic or mild cases were put in-home quarantine (Ministry of Health \& Family Welfare 2020).

Table 1: COVID-19 situation by WHO Region/Country. Confirmed cases including deaths as of 29 May 2021 reported to WHO of some topmost countries [Source: COVID Intel Database (WHO)].

\begin{tabular}{|c|c|c|c|c|c|}
\hline Name & $\begin{array}{c}\text { WHO } \\
\text { Region }\end{array}$ & \begin{tabular}{|c|}
$\begin{array}{c}\text { COVID-19 cases } \\
\text { (cumulative } \\
\text { total) }\end{array}$ \\
\end{tabular} & $\begin{array}{c}\text { COVID-19 related } \\
\text { deaths } \\
\text { (cumulative total) }\end{array}$ & \begin{tabular}{|c} 
Deaths per \\
million of \\
COVID-19 cases
\end{tabular} & $\begin{array}{c}\text { Percentage } \\
\text { of deaths }\end{array}$ \\
\hline \multicolumn{2}{|c|}{ Global } & $168,599,045$ & $3,507,477$ & 20803.66 & 2.08 \\
\hline $\begin{array}{c}\text { United States of } \\
\text { America }\end{array}$ & Americas & $32,869,009$ & 586,890 & 17855.42 & 1.79 \\
\hline India & $\begin{array}{c}\text { South- } \\
\text { East Asia }\end{array}$ & $27,555,457$ & 318,895 & 11572.84 & 1.16 \\
\hline Brazil & Americas & $16,274,695$ & 454,429 & 27922.43 & 2.79 \\
\hline France & Europe & $5,535,701$ & 108,354 & 19573.67 & 1.96 \\
\hline $\begin{array}{c}\text { Russian } \\
\text { Federation }\end{array}$ & Europe & $5,044,459$ & 120,406 & 23868.96 & 2.39 \\
\hline $\begin{array}{l}\text { The United } \\
\text { Kingdom }\end{array}$ & Europe & $4,473,681$ & 127,758 & 28557.69 & 2.86 \\
\hline Italy & Europe & $4,205,970$ & 125,793 & 29908.20 & 2.99 \\
\hline Germany & Europe & $3,669,870$ & 88,187 & 24030.01 & 2.40 \\
\hline Spain & Europe & $3,663,176$ & 79,888 & 21808.40 & 2.18 \\
\hline
\end{tabular}

During the period of the year into a pandemic, studies have shown genetic variability in various factors which may result in differential epidemiology of disease across the globe or differential clinical presentations or outcomes. These include polymorphism in ACE2 receptor, genetic variability across three HLA molecules (HLA B* 46:01 variant vulnerable to SARS-CoV-2 infection while HLA $B^{*}$ 15:03 variant as protective), locus $3 \mathrm{p} 31.21$ being associated to the disease susceptibility gene cluster on $\mathrm{ABO}$ group with $\mathrm{O}$ blood group conferring protection (Severe Covid et al., 2020). Recently one author has hypothesized the genetic variability exacerbating NET formation resulting in exaggerated 
inflammatory response and coagulopathy (Thierry 2020). Any imbalance between the protective immune response and immune dysregulation determines the final outcome of the disease (Fig. 1), so what is favoring the Indian population towards a better outcome; is the Indian population harboring any protective immune response needs to be elicited. In the upcoming era of precision medicine, it becomes important to study immunogenetics at individual levels to determine the treatment of disease.

Therefore, understanding the dynamics of immune response in patients with different outcomes of the disease may provide the immunological blueprint of protective immunity against COVID-19. Although there is little evidence available on the characteristics of humoral immune response to SARS-CoV-2, the crucial role of antibodies in conferring protection is slowly emerging. Though recent data on healthy blood donors and mild cases of COVID-19 suggested that $70 \%$ of the Indian population have strong traits of durable immune memory (Ansari et al., 2020).

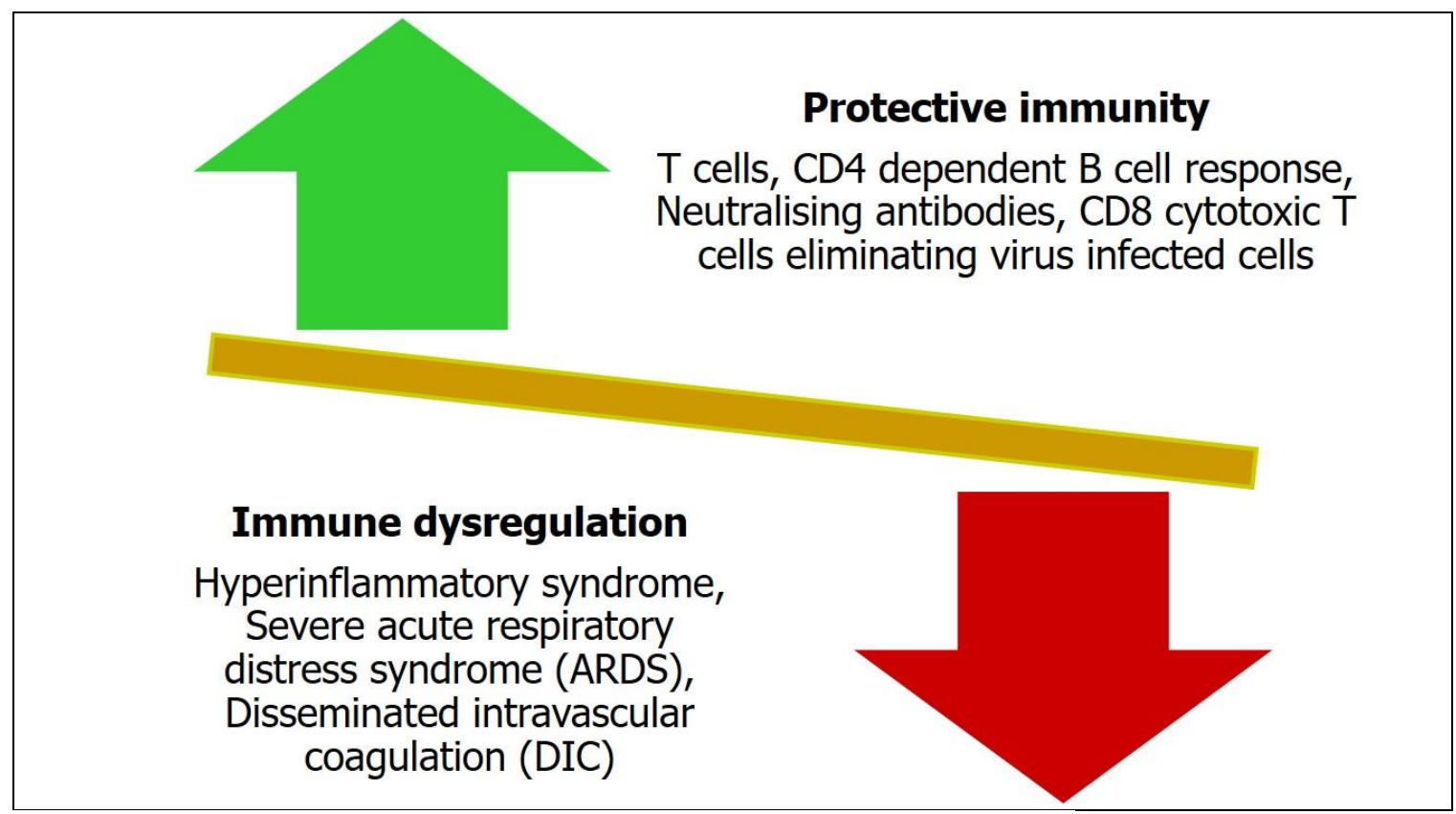

Fig. 1: COVID-19 Protective immunity and inflammatory spectra.

Since viruses are host-dependent, they co-evolve with the hosts and devise many strategies to evade the host immune response. The spike (S) glycoprotein of SARS-CoV-2 has a strong affinity for ACE-2 host receptor. The Receptor binding domain (RBD) is variable and differs between SARS-CoV-2 and SARS$\mathrm{CoV}$, but remains an appropriate target for a vaccine, alongside $\mathrm{S}$ protein (Chiu and Openshaw 2015; Figgett et al., 2013; Smulski and Eibel 2018). Antibodies against $\mathrm{S}$ protein may play a crucial role in controlling the virus dissemination by inhibiting its interaction with ACE-2 receptor on host cells, however, it is too early to speculate that whether the antibodies formed during SARS-CoV-2 infection have a long-lasting immunity or if non-neutralizing in nature, the antibodies can prove to be detrimental during reinfections, facilitating antibodydependent enhancement (Chiu and Openshaw 2015; Figgett et al., 2013; Hotez et al., 2020; Jartti et al., 2005).

There are similarities between fatal SARS-CoV and H5N1 influenza virus infections with associated lung infiltration by macrophages $(\mathrm{Gu}$ and Korteweg 2007; Ng et al., 2006; van den 
Brand et al., 2014). However, the observed virus clearance from the lungs of SARS or fatal H5N1 infection patients at the time of death raises doubts regarding mortality due to the virus in the lungs (Channappanavar and Perlman 2017; Hendrickson and Matthay 2013; Korteweg and $\mathrm{Gu}$ 2008). SARS-CoV-2 did not show widespread infection amongst children nor many fatalities were reported (Zimmermann and Curtis 2020). Unlike other infections, the transmission to children in the Indian population has shown a dramatic resistance in acquiring SARS-CoV-2. On comparison of immune phenotypes, a study by Rathore et al. observed a significantly high number of monocytes, NK cells, $\mathrm{CD}^{+}{ }^{\mathrm{T}}$ cells, naïve $\mathrm{B}$ cells and memory $\mathrm{CD}^{+}{ }^{+} \mathrm{T}$ cells prominent amongst Indian infants as compared to infants born in US (Rathore et al., 2018).

\subsection{Role of Cytokine Gene Polymorphisms in Disease Susceptibility and Severity:}

Considering that India has a diverse ethnicity and is endemic to several parasitic and viral infections, it is difficult to unequivocally establish the role of $\mathrm{T}$ and $B$ cells in defense against SARSCOV-2. A team of researchers observed better survival capacity amongst Indians, probably possessing unique KIR (killer cell immunoglobulin-like receptors) genes as a result of natural selection to survive the environmental challenges (2008; Mukherjee et al., 2009; Rajalingam et al., 2008). Furthermore, childhood immunization and exposure to diverse microbes challenge the immune system and evolve various mechanisms to defend against the pathogens. The haplotype HLA variability can occur under stress as a compensatory mechanism during infection and determines the eventual outcome of a disease. On the other hand, immunerelated genes for cytokines are polymorphic and the cytokine gene expression and disease manifestation may vary in different ethnic populations.
Cytokines have a key role to play not only in the defense against pathogens but their genes are the candidates for host susceptibility to the onset of an active disease too (Wu et al., 2019). It is evident from previous studies that cytokine production may vary during disease progression which is strictly under genetic control. Several polymorphisms of promoter and coding regions of cytokines influence not only their production and risk of disease but also disturbs the balance between pro-inflammatory and anti-inflammatory cytokines production (Jarduli et al., 2013). Hence, the genetic background of an individual may influence the onset and progression of the disease and the cytokine release storm (CRS), leading to critical illness and fatal outcome is the hallmark of severe COVID-19 infection.

There is evidence that high IL-2, IFN- $\gamma$, granulocyte colony-stimulating factor (G-CSF), IL-17, monocyte chemoattractant protein (MCP)-1,TNF- $\alpha$, macrophage inflammatory protein (MIP)-1 alpha and IL-6 production after viral infection have been found to be associated with poor outcomes (Tisoncik et al., 2012). The IL-1 $\beta$ secreted by endothelial cells through the nucleotide-binding domain of (NOD)-like receptor protein 3 (NLRP3), inflammasome mechanisms contribute to flu-induced inflammation in lung cells observed after H1N1 infection. This implies that with a polymorphism in IL-1 $\beta$ promoter, $\mathrm{T}$ to $\mathrm{C}$ transition at position -31 (rs16944), can result in high IL-1 $\beta$ production inducing significantly higher lung damage after influenza A virus infection (Chan et al., 2020). Evidently, influenza viruses take advantage of single nucleotide polymorphism (SNP)-driven variations in host cytokines that alter the transcriptional activity of their genes. Additionally, rs2275913 SNP of the IL-17 gene leading to altered IL-17 expression is related to the increased severity of acute bronchiolitis severity (El-Omar et al., 2000; Griffiths et al., 2015; Kim et al., 
2015; Pinto et al., 2017).

One of the most important responses to viral respiratory infections in airway cells is interferon secretion and the gene IL-28 is shown to play an important role in augmenting cytotoxic $\mathrm{CD} 8^{+} \mathrm{T}$ cells thus affecting the disease outcome (Daneshvar et al., 2016). The contribution of SNP polymorphisms located at rs8099917 site near the IL-28b gene; of type III interferon in spontaneous clearance and sustained virological response to IFN- $\alpha$ and ribavirin treatment in hepatitis $\mathrm{C}$ virus ( $\mathrm{HCV}$ ) patients is exhibited as a unique anti-inflammatory property of IFN- $\lambda$ (Rauch et al., 2010; Shaker and Sadik 2012).

Meanwhile, the function of other anti-inflammatory cytokines cannot be underestimated. IL-10 regulates and suppresses the expression of proinflammatory cytokines by macrophages to limit the damage caused by viral and bacterial infections (Rojas et al., 2017). The frequency of certain IL-10 SNPs renders Mexican patients susceptible to severe disease, while other SNPs seem protective in nature (Martinez-Ocana et al., 2013). The rs1800872 polymorphism, located at the 5'-flanking regions of IL-10 promoter controlling the transcription and expression of IL-10, is related to increased intensity of autoimmune and infectious diseases (Zhang et al., 2012; Zhao et al., 2017). It has been shown that rs 1800872 SNP enhanced resistance to severe RSV infection and IL-10 balance could reduce the harmful effects of the immune system (Schuurhof et al., 2011; Yu et al., 2017). Therefore, evaluation of these polymorphisms in relation to SARS-CoV2 may be useful in identifying and distinguishing the degree of immune reactivity in different populations across the globe as studied earlier in the case of influenza.

High serum levels of proinflammatory cytokines (IFN- $\gamma$, IL- 1 , IL6 , IL-12, TGF- $\beta$ ) and chemokines (CCL2, CXCL-10, CXCL-9, IL-8) were found in
SARS patients with severe disease compared to individuals with uncomplicated SARS. Conversely, SARS patients with severe disease had very low levels of anti-inflammatory cytokines and chemokines. Early studies have shown that IL-1 $\beta$, IL-10, IL-17 and IL-28 gene polymorphisms are associated with the inflammatory process affecting the outcome of influenza virus A/H3N2 infection (Keshavarz et al., 2019; Rogo et al., 2016). It was observed that in a dominant mode, IL-10 rs1800896 G allele was significantly negatively associated with disease severity during H1N1 pandemic (Choudhary et al., 2018). Hence, there is enough evidence to speculate a varied response of cytokine gene polymorphism in COVID-19 patients of different ethnicities.

\subsection{Cytokine Gene Polymorphisms Underpinning Indian COVID-19 Response?}

Till now no study has reported on the role of host gene polymorphism and the impact of defense on SARS-CoV-2. Polymorphisms (SNPs) in the TNF- $\alpha$, IFN- $\gamma$, IL-10, and CCL2 have been shown to be associated with variations in the levels of the respective cytokines. An overview of genome data on the Indian population shows a significant allele and genotype distribution in IL-10 -819 C/T and $-592 \mathrm{C} / \mathrm{A}$ and IFN- $\gamma+874 \mathrm{~A} / \mathrm{T}$ gene polymorphisms leading to dermatological manifestations in Indian subjects. The resultant haplotypes were responsible for high IL-10 and low IFN- $\gamma$ production in the Indian population (Jain et al., 2017).

Our previous cytokine

polymorphism study showed higher IL-10 -1082 AG and lower AA genotype with decreased A allele frequency; higher IL-10 -819 CC and lower TT genotype frequency with decreased $\mathrm{T}$ allele frequency; and lower IL-10 -592 AC genotype frequency in healthy subjects in North India (Dar et $a l$. , 2016). The most frequent haplotype detected was GCC (-1082G, -819C, and 592C) in these healthy individuals 
depicting an ability of higher IL-10 secretion. IL-10 promoter $-1082 \mathrm{G}$ allele or GCC haplotype is associated with increased IL-10 production, while ATA and ACC haplotypes are generally assumed to be a responder for low IL-10. Considering the immunosuppressive role of IL-10, we suggest that the high carriage of high producer GCC rather than low producers ATA and ACC haplotypes by the Indian population most likely have a role in protection against COVID-19. It will be interesting to understand that high IL-10 manifested in the Indian population may be a reason for the mild manifestation of SARS-CoV-2 amongst Indians.

Conversely, a decreased IFN- $\gamma$ +874 AT genotype frequency in the same healthy Indian population pointed towards lower IFN- $\gamma$ production during subsequent antigen exposure (Dar et al., 2016). Further, antigen-promoted high IL-10 production exerts an immune regulatory effect by suppressing IFN- $\gamma$ production. IL-10 is known to affect B cell survival, proliferation, differentiation and immunoglobulin production. In addition to IFN- $\gamma$, IL-10 also inhibits IL-2 secretion by Th1 cells (de Moreno de Leblanc et al., 2011), thereby, decreasing T cell-mediated immunity but augmenting humoral immunity. Effects of IL-10 on antigen uptake by dendritic cells, increasing expression of TLRs, and stimulating NK cell cytotoxicity to suggest its importance in limiting inflammation, executing control over the regulation of immune reactions and supporting immunoglobulin production by $\mathrm{B}$ cells. This probably explains the manifestation of mild infection with rapid recovery amongst Indian patients. Hence, large-scale epidemiological data would be beneficial to study SARS-COV-2 infection in Indian adults.

The cytokines are expressed de novo in response to pathogens and a gene polymorphism may affect transcriptional regulation and severity of the disease. Inhibition of IFN- $\gamma$ by high IL-10 production delays the clearance of intracellular bacteria. Genomics and SNP database suggest that Indian population homozygous (AA) for IFN- $\gamma+874$ have a low production of IFN- $\gamma$ in comparison to AT/TT genotypes carriers as evident in mycobacterial tuberculosis. The $\mathrm{T}$ allele correlates with high IFN- $\gamma$ expression. The homozygous TT genotype is associated with the ability to produce high levels of IFN- $\gamma$, the heterozygous TA genotype with intermediate levels, and the homozygous AA genotype with lower levels (LópezMaderuelo et al., 2003). A significant percentage of the Indian population carrying the lower IFN- $\gamma$ producing genotype (Dar et al., 2016), may provide an advantage for not producing exaggerated immune response during mild to moderate infection. The lower IFN- $\gamma$ production further cause's poor macrophage activation and slow disease progression. Early inhibition of IFN- $\beta$ may prove beneficial in reducing inflammation and $\mathrm{T}$ cell apoptosis. So, we may hypothesize that polymorphisms of IL-10 and IFN- $\gamma$ contribute to control over disease progression and early resolution of symptoms in COVID-19 in the Indian population.

Recently, Th17 cells became the center of extensive research and its hallmark cytokine IL-17 dysregulation has contributed to the progression of cancer, inflammatory disease, autoimmune disorder, and clearance of viral or microbial pathogens (Long et al., 2015; Lukacs et al., 2010; Mukherjee et al., 2011). In viral diseases, the presence of the $G$ allele in IL-17 rs2275913 SNP increases the risk of influenza A (H1N1) infection. In contrast, these variations may also regulate immune response and provide protection against severe infection. Early data suggest that patients carrying allele 'A' of IL-17 rs2275913 SNP lack the ability to control their inflammatory response resulting in ineffective immune $\mathrm{T}$ cells response against influenza virus infection. 
Furthermore, H1N1 pandemic influenza virus-induced Th17-secreted IL-17 resulting in mild and severe disease shows that flu viruses actually benefitted from IL-17 SNPs in developing infection and lung injury. Briefly, IL-10 rs1800872 and IL-28; rs8099917 SNPs are not associated with the risk of infection (Echeverria et al., 2018; Peresi et al., 2013).

Meanwhile, IL-28, a member of the IFN- $\gamma$ family has IL-10 like antiviral properties and induces survival signaling in host cells. An early study showed significantly higher rates of seroconversion after influenza vaccination of transplant patients harboring minoralleles in the IL-28b gene (rs8099917; TG or GG) (Egli et al., 2014; Linnik and Egli 2016). TG or GG, minor-allele genotypes of IL-28b seem strongly associated with the immune suppressive property and host protection when compared with the majorallele TT with severe influenza infections. However, few studies have also shown that IL-28 rs8099917 SNP is associated with flu A (H3N2) and HCV infections in Iranian and Italian patients, respectively (Keshavarz et al., 2019; Rogo et al., 2016; Sticchi et al., 2013). In HCV patients achieving sustained virologic response (SVR), 63\% had protective TT genotype of IL-28b gene polymorphism while $37 \%$ carried TG/GG genotypes (Egli et al., 2014; $\mathrm{Mi}$ et al., 2014). Hence, the involvement of IL-28b polymorphism in the Indian population has to be defined for their protective role in COVID-19 patients.

\subsection{Heterologous Immunity:}

There is a wide spectrum of clinical disease and the varied immune response is a consequence of multiple factors which include the host genetics, epidemiological variables, duration of viral exposure and other co-morbidities. Due to the diverse microbial community, cross-reactive memory $\mathrm{T}$ cell population to various recall antigens provides an additional advantage in minimizing the severity of infections amongst the Indian population. It is well described that the high rate of viral mutation makes the conventional B-cell-based vaccines against RNA respiratory viruses virtually impossible; but T-cell epitopes shown to be cross-reactive in RV may prove to be useful (Selin et al., 2004). However, the use of T-cell-based vaccines may paradoxically enhance disease pathology (Panagioti et al., 2018). Alternatively, the use of anti-inflammatory drugs or blocking or depleting of cytokines (TNF, IL-4, IL13 and IL-12) and chemokines including CCL11 (eotaxin), CCL5 (RANTES), or the receptor CCR1 ICOS and OX40L (Stegelmeier et al., 2019); are effective in reducing disease burden though should be used with caution.

The general aspects of immunemediated pathogenesis in COVID-19 have been enumerated well. Nevertheless, multiple pieces of evidence suggest that a host genotype database can generate useful predictions of a disease progression in a particular population. Furthermore, it may also assist in predicting the response to the treatment and outcome of an infectious disease. Antiviral host-miRNAs may likely control the viral pathogenesis as a part of host responses to viral infection. A recent study revealed that nine host miRNAs that can potentially target SARSCoV-2 genes, do not have targets in SARS and MERS genomes. Hence, human microRNA-27b (hsa-miR-27b) is the only unique miRNA that has a target gene in the Indian SARS-CoV-2 genome (Liang et al., 2018; Rahila Sardar 2020). As observed earlier in $M$. tuberculosis infection, miRNAs play an important role in regulating host anti-mycobacterial defense through an inflammatory response. MicroRNA-27b mediated by the TLR-2/ MyD88/ NF-kB signaling pathway suppresses the production of proinflammatory factors (IL-1 $\beta$, IL-6, TNF- $\alpha$, iNOS), prevents excessive inflammation during $M$. tuberculosis infection (Liang et al., 2018). The study revealed a novel role of the miR-27b in the regulation of inflammatory response, worth exploring in 
COVID-19 cases for a potential molecular host defense mechanism.

Environmental and socioeconomic factors such as tropical humidity, overcrowding, and close contacts of infected household members constitute well-known risks. Despite several reasons for an impending rise in the number of cases, the fatalities have been proportionately low. Considering the genetic composition and non-synonymous cytokine polymorphisms, a certain link between SARS-CoV-2 severity, clinical spectrum and outcome of the disease defines a distinct predisposition amongst the Indian population. To know the extent of morbidity and mortality associated with SARS-CoV-2, it is important to investigate cytokine gene polymorphism in asymptomatic and symptomatic patients which may offer a ray of hope of containing this simmering pandemic.

\section{Conclusion:}

The genetic make-up of the Indian population is likely modulating immunopathology associated with COVID-19. Cytokine polymorphisms prevalent in the Indian population seem to mellow down the cytokine storm which may be responsible for the lower rate of severe illness and mortality. However, further genetic epidemiology studies are required to substantiate the hypothesis.

\section{Declarations}

Funding: Not applicable

Conflicts of interest/Competing interests: Shukla DAS, Chhavi GUPTA, Naseem AKHTER, Charu JAIN, Sidharth SONTHALIA, Saif AHMAD and Sajad Ahmad DAR have no conflicts of interest to declare that are relevant to the content of this article.

Ethics approval: Not applicable

Consent to participate: Not applicable

Consent for publication: Not applicable REFERENCES

A.R. Sharma GB, M. Kumar, A. Mishra, R. Singla, A. Singh, R.S. Singh, B. Medhi. (2020). BCG as a gamechanger to prevent the infection and severity of COVID-19 pandemic?. Allergol Immunopathol (Madr), 48:507-517.

Ansari A, Arya R, Sachan S, Jha SN, Kalia A, Lall A, Sette A, Grifoni A, Weiskopf D, Coshic P and others. (2020). Immune memory in mild COVID-19 patients and unexposed donors from India reveals persistent $\mathrm{T}$ cell responses after SARS-CoV-2 infection. 2020. 11. 16.20232967.

Badawi A. (2020). Hypercytokinemia and Pathogen-Host Interaction in COVID-19. Journal of Inflammation Research, 13:255261.

Chan JF, Zhang AJ, Yuan S, Poon VK, Chan CC, Lee AC, Chan WM, Fan Z, Tsoi HW, Wen L and others. (2020). Simulation of the clinical and pathological manifestations of Coronavirus Disease 2019 (COVID-19) in golden Syrian hamster model: implications for disease pathogenesis and transmissibility. Clinical infectious diseases: an official publication of the Infectious Diseases Society of America.

Channappanavar R, Perlman S. (2017). Pathogenic human coronavirus infections: causes and consequences of cytokine storm and immunopathology. Seminars in immunopathology, 39:529-539.

Chiu C, Openshaw PJ. (2015). Antiviral B cell and $\mathrm{T}$ cell immunity in the lungs. Nature immunology, 16:1826.

Choudhary ML, Alagarasu K, Chaudhary U, Kawale S, Malasane P, Gurav YK, Padbidri V, Kadam D, Sangle SA, Salvi S and others. (2018). Association of Single Nucleotide Polymorphisms in TNFA and IL10 Genes with Disease Severity in Influenza A/H1N1pdm09 Virus Infections: A Study from Western 
India. Viral immunology, 31:683688.

Daneshvar M, Nikbin M, Talebi S, Javadi F, Aghasadeghi MR, Mahmazi S, Sadat SM. (2016). Role of IL28-B Polymorphism (rs12979860) on Sustained Virological Response to Pegylated Interferon/Ribavirin in Iranian Patients with Chronic Hepatitis C. Iranian Red Crescent medical journal, 18: e28566.

Dar SA, Janahi EM, Haque S, Akhter N, Jawed A, Wahid M, Ramachandran VG, Bhattacharya SN, Banerjee BD, Das S. (2016). Superantigen influence in conjunction with cytokine polymorphism potentiates autoimmunity in systemic lupus erythematosus patients. Immunologic Research, 64:100112.

de Moreno de Leblanc A, Del Carmen S, Zurita-Turk M, Santos Rocha C, van de Guchte M, Azevedo V, Miyoshi A, Leblanc JG. (2011). Importance of IL-10 modulation by probiotic microorganisms in gastrointestinal inflammatory diseases. ISRN Gastroenterol, 2011:892971.

Echeverria N, Chiodi D, Lopez P, Sanchez Ciceron A, Angulo J, Lopez-Lastra M, Silvera P, Canavesi A, Bianchi C, Colistro V and others. (2018). IL28B gene polymorphism rs12979860, but not rs8099917, contributes to the occurrence of chronic HCV infection in Uruguayan patients. Virology journal, 15:40.

Egli A, Santer DM, O'Shea D, Barakat K, Syedbasha M, Vollmer M, Baluch A, Bhat R, Groenendyk J, Joyce MA and others. (2014). IL-28B is a key regulator of $\mathrm{B}$ - and $\mathrm{T}$-cell vaccine responses against influenza. PLoS pathogens, 10: e1004556.

El-Omar EM, Carrington M, Chow WH, McColl KE, Bream JH, Young
HA, Herrera J, Lissowska J, Yuan CC, Rothman N and others. (2000). Interleukin-1 polymorphisms associated with increased risk of gastric cancer. Nature, 404:398402.

Figgett WA, Fairfax K, Vincent FB, Le Page MA, Katik I, Deliyanti D, Quah PS, Verma P, Grumont R, Gerondakis S and others. (2013). The TACI receptor regulates $\mathrm{T}$ cell-independent marginal zone $\mathrm{B}$ cell responses through innate activation-induced cell death. Immunity, 39:573-83.

Griffiths SJ, Dunnigan CM, Russell CD, Haas JG. (2015). The Role of Interferon-lambda Locus Polymorphisms in Hepatitis C and Other Infectious Diseases. Journal of innate immunity, 7:231-42.

Gu J, Korteweg C. (2007). Pathology and pathogenesis of severe acute respiratory syndrome. The American journal of pathology, 170:1136-47.

Hendrickson CM, Matthay MA. (2013). Viral pathogens and acute lung injury: investigations inspired by the SARS epidemic and the 2009 H1N1 influenza pandemic. Seminars in respiratory and critical care medicine, 34:475-86.

Hoffmann M K-WH, Schroeder S, Krüger $\mathrm{N}$, Herrler $\mathrm{T}$, Erichsen $\mathrm{S}$, Schiergens TS, Herrler G, Wu NH, Nitsche A, Müller MA, Drosten C, Pöhlmann S. (2020). SARS-CoV-2 cell entry depends on ACE2 and TMPRSS 2 and is blocked by a clinically proven protease inhibitor. Cell, 181:271-280.

Hotez PJ, Corry DB, Bottazzi ME. (2020). COVID-19 vaccine design: the Janus face of immune enhancement. Nature reviews. Immunology, 20:347-348.

Jain C, Das S, Ramachandran VG, Saha R, Bhattacharya SN, Dar S. (2017). Malassezia Yeast and Cytokine 
Gene Polymorphism in Atopic Dermatitis. Journal of clinical and diagnostic research: JCDR, 11: DC01-DC05.

Jain VK, Iyengar K, Vaish A, Vaishya R. (2020). Differential mortality in COVID-19 patients from India and western countries. Diabetes Metab Syndr, 14:1037-1041.

Jarduli LR, Sell AM, Reis PG, Sippert EA, Ayo CM, Mazini PS, Alves HV, Teixeira JJ, Visentainer JE. (2013). Role of HLA, KIR, MICA, and cytokines genes in leprosy. BioMed research international, 2013: 989837.

Jartti T, Makela MJ, Vanto T, Ruuskanen O. (2005). The link between bronchiolitis and asthma. Infectious disease clinics of North America, 19:667-89.

Keshavarz M, Namdari H, Farahmand M, Mehrbod P, Mokhtari-Azad T, Rezaei F. (2019). Association of polymorphisms in inflammatory cytokines encoding genes with severe cases of influenza $\mathrm{A} / \mathrm{H} 1 \mathrm{~N} 1$ and $\mathrm{B}$ in an Iranian population. Virology journal, 16:79.

Kim KS, Jung H, Shin IK, Choi BR, Kim DH. (2015). Induction of interleukin-1 beta (IL-1beta) is a critical component of lung inflammation during influenza A (H1N1) virus infection. Journal of medical virology, 87:1104-12.

Korteweg C, Gu J. (2008). Pathology, molecular biology, and pathogenesis of avian influenza $\mathrm{A}$ (H5N1) infection in humans. The American journal of pathology, 172:1155-70.

Liang S, Song Z, Wu Y, Gao Y, Gao M, Liu F, Wang F, Zhang Y. (2018). MicroRNA-27b Modulates Inflammatory Response and Apoptosis during Mycobacterium tuberculosis Infection. Journal of Immunology, 200:3506-3518.
Linnik JE, Egli A. (2016). Impact of host genetic polymorphisms on vaccine induced antibody response. Human vaccines \& immunotherapeutics, 12:907-15.

Long ZW, Yu HM, Wang YN, Liu D, Chen YZ, Zhao YX, Bai L. (2015). Association of IL-17 polymorphisms with gastric cancer risk in Asian populations. World journal of gastroenterology, 21:5707-18.

López-Maderuelo D, Arnalich F, Serantes R, González A, Codoceo R, Madero R, Vázquez JJ, Montiel C. (2003). Interferon-gamma and interleukin-10 gene polymorphisms in pulmonary tuberculosis. American journal of respiratory and critical care medicine, 167:970-5.

Lukacs NW, Smit JJ, Mukherjee S, Morris SB, Nunez G, Lindell DM. (2010). Respiratory virus-induced TLR7 activation controls IL-17associated increased mucus via IL23 regulation. Journal of Immunology, 185:2231-9.

Mao R, Qiu Y, He JS, Tan JY, Li XH, Liang J, Shen J, Zhu LR, Chen Y, Iacucci $M$ and others. (2020). Manifestations and prognosis of gastrointestinal and liver involvement in patients with COVID-19: a systematic review and meta-analysis. Lancet Gastroenterol Hepatol, 5:667-678.

Martinez-Ocana J, Olivo-Diaz A, SalazarDominguez T, Reyes-Gordillo J, Tapia-Aquino C, MartinezHernandez F, Manjarrez ME, Antonio-Martinez M, ContrerasMolina A, Figueroa-Moreno R and others. (2013). Plasma cytokine levels and cytokine gene polymorphisms in Mexican patients during the influenza pandemic $\mathrm{A}(\mathrm{H} 1 \mathrm{~N} 1)$ pdm09. Journal of clinical virology: the official publication of the Pan 
American Society for Clinical Virology, 58:108-13.

Mi Y, Gao YT, Jiao XL, Guo H, Liu T, Jing L, Shi WX, Du Z. (2014). The role of interleukin-28b gene polymorphisms in chinese patients with chronic hepatitis $\mathrm{C}$ treated with pegylated interferon and ribavirin. Hepatitis monthly, 14: e18793.

Ministry of Health \& Family Welfare GoI. (2020). Revised guidelines for Home Isolation of very mild/presymptomatic COVID-19 cases. Online.

Mukherjee S, Lindell DM, Berlin AA, Morris SB, Shanley TP, Hershenson MB, Lukacs NW. (2011). IL-17-induced pulmonary pathogenesis during respiratory viral infection and exacerbation of allergic disease.The American journal of pathology, 179:248-58.

Mukherjee S, Sarkar-Roy N, Wagener DK, Majumder PP. (2009). Signatures of natural selection are not uniform across genes of innate immune system, but purifying selection is the dominant signature. Proceedings of the National Academy of Sciences of the United States of America, 106:7073-8.

$\mathrm{Ng}$ WF, To KF, Lam WW, Ng TK, Lee KC. (2006). The comparative pathology of severe acute respiratory syndrome and avian influenza A subtype H5N1--a review. Human pathology, 37:38190.

Panagioti E, Klenerman P, Lee LN, van der Burg SH, Arens R. (2018). Features of Effective $\mathrm{T}$ CellInducing Vaccines against Chronic Viral Infections. Frontiers in immunology, 9:276.

Peresi E, Oliveira LR, da Silva WL, da Costa EA, Araujo JP, Jr., Ayres JA, Fortes MR, Graviss EA, Pereira AC, Calvi SA. (2013). Cytokine Polymorphisms, Their
Influence and Levels in Brazilian

Patients with Pulmonary

Tuberculosis during

Antituberculosis Treatment.

Tuberculosis research and treatment, 2013:285094.

Pinto LA, LA DEAL, Mocellin M, Acosta $\mathrm{P}$, Caballero MT, Libster R, Vargas JE, Polack F, Comaru T, Stein RT and others. (2017). IL-8/IL-17 gene variations and the susceptibility to severe viral bronchiolitis. Epidemiology and infection, 145:642-646.

Qin C, Zhou L, Hu Z, Zhang S, Yang S, Tao Y, Xie C, Ma K, Shang K, Wang W and others. (2020). Dysregulation of Immune Response in Patients with Coronavirus 2019 (COVID-19) in Wuhan, China. Clinical Infectious Diseases, 71:762-768.

Rahila Sardar DS, Shweta Birla, Dinesh Gupta. (2020). Comparative analyses of SAR-CoV2 genomes from different geographical locations and other coronavirus family genomes reveals unique features potentially consequential to host-virus interaction and pathogenesis. bioRxiv, CSHL.

Rajalingam R, Du Z, Meenagh A, Luo L, Kavitha VJ, Pavithra-Arulvani R, Vidhyalakshmi A, Sharma SK, Balazs I, Reed EF and others. (2008). Distinct diversity of KIR genes in three southern Indian populations: comparison with world populations revealed a link between KIR gene content and prehistoric human migrations. Immunogenetics, 60:207-17.

Rathore DK, Holmes TH, Nadeau KC, Mittal P, Batra A, RosenbergHasson Y, Sopory S, Gupta R, Chellani HK, Aggarwal KC and others. (2018). Differences in multiple immune parameters between Indian and U.S. infants. PloS one, 13: $\mathrm{e} 0207297$. 
Rauch A, Kutalik Z, Descombes P, Cai T, Di Iulio J, Mueller T, Bochud M, Battegay M, Bernasconi E, Borovicka J and others. (2010). Genetic variation in IL28B is associated with chronic hepatitis $\mathrm{C}$ and treatment failure: a genomewide association study. Gastroenterology, 138:1338-45, 1345 e1-7.

Rogo LD, Rezaei F, Marashi SM, Yekaninejad MS, Naseri M, Ghavami N, Mokhtari-Azad T. (2016). Seasonal influenza $\mathrm{A} / \mathrm{H} 3 \mathrm{~N} 2$ virus infection and IL1Beta, IL-10, IL-17, and IL-28 polymorphisms in Iranian population. Journal of medical virology, 88:2078-2084.

Rojas JM, Avia M, Martin V, Sevilla N. (2017). IL-10: A Multifunctional Cytokine in Viral Infections. Journal of immunology research, 2017:6104054.

Schuurhof A, Janssen R, de Groot H, Hodemaekers HM, de Klerk A, Kimpen JL, Bont L. (2011). Local interleukin-10 production during respiratory syncytial virus bronchiolitis is associated with post-bronchiolitis wheeze. Respiratory research, 12:121.

Sehrawat S RB. (2020). Does the hygiene hypothesis apply to COVID-19 susceptibility? Microbes and Infection, 22:400-402.

Selin LK, Cornberg M, Brehm MA, Kim SK, Calcagno C, Ghersi D, Puzone R, Celada F, Welsh RM. (2004). CD8 memory $T$ cells: crossreactivity and heterologous immunity. Seminars in immunology, 16:335-47.

Severe Covid GG, Ellinghaus D Degenhardt F, Bujanda L, Buti M, Albillos A, Invernizzi P, Fernandez J, Prati D, Baselli $G$ and others. (2020). Genomewide Association Study of Severe Covid-19 with Respiratory Failure. The New
England Journal of Medicine, 383:1522-1534.

Shah VK, Firmal P, Alam A, Ganguly D, Chattopadhyay S. (2020). Overview of Immune Response During SARS-CoV-2 Infection: Lessons from the Past. Frontiers in Immunology, 11:1949.

Shaker OG, Sadik NA. (2012). Polymorphisms in interleukin-10 and interleukin-28B genes in Egyptian patients with chronic hepatitis $\mathrm{C}$ virus genotype 4 and their effect on the response to pegylated interferon/ribavirintherapy. Journal of gastroenterology and hepatology, 27:1842-9.

Smulski CR, Eibel H. (2018). BAFF and BAFF-Receptor in B Cell Selection and Survival. Frontiers in immunology, 9:2285.

Stegelmeier AA, van Vloten JP, Mould RC, Klafuric EM, Minott JA, Wootton SK, Bridle BW, Karimi K. (2019). Myeloid Cells during Viral Infections and Inflammation. Viruses 11.

Sticchi L, Di Biagio A, Rappazzo E, Setti M, De Rosa G, De Hoffer L, Nicolini L, Prinapori R, Bruzzone B. (2013). Rs12979860 and rs8099917 single nucleotide polymorphisms of interleukin-28B gene: simultaneous genotyping in caucasian patients infected with hepatitis $\mathrm{C}$ virus. Journal of preventive medicine and hygiene, 54:83-6.

Thierry AR. (2020). Host genetic factors associated with COVID-19 call for precision medicine. In Precision Clinical Medicine. pp 228-234.

Tisoncik JR, Korth MJ, Simmons CP, Farrar J, Martin TR, Katze MG. (2012). Into the eye of the cytokine storm. Microbiology and molecular biology reviews: $M M B R, 76: 16-32$.

Vaduganathan M VO, Michel T, McMurray J, Pfeffer M, Solomon 
S. (2020). Renin-AngiotensinAldosterone System Inhibitors in Patients with Covid-19. The New England Journal of Medicine, 382:1653-1659.

Van den Brand JM, Haagmans BL, van Riel D, Osterhaus AD, Kuiken T. (2014). The pathology and pathogenesis of experimental severe acute respiratory syndrome and influenza in animal models. Journal of comparative pathology, 151:83-112.

WHO (2020). WHO coronavirus (COVID19) dashboard. Retrieved from https://covid19.who.int/.

Wiersinga WJ, Rhodes A, Cheng AC, Peacock SJ, Prescott HC. (2020). Pathophysiology, Transmission, Diagnosis, and Treatment of Coronavirus Disease 2019 (COVID-19): A Review. JAMA: The Journal of the American Medical Association, 324:782-793.

Wu S, Wang MG, Wang Y, He JQ. (2019). Polymorphisms of cytokine genes and tuberculosis in two independent studies. Scientific reports, 9:2507.

Xu Z, Shi L, Wang Y, Zhang J, Huang L, Zhang C, Liu S, Zhao P, Liu H, Zhu L and others. (2020). Pathological findings of COVID19 associated with acute respiratory distress syndrome. The Lancet Respiratory Medicine, 8:420-422.

Yu Y, Chen Y, Wang FL, Sun J, Li HJ, Liu JM. (2017). Cytokines Interleukin 4 (IL-4) and Interleukin 10 (IL-10) Gene Polymorphisms as
Potential Host Susceptibility Factors in Virus-Induced Encephalitis. Medical science monitor: international medical journal of experimental and clinical research, 23:4541-4548.

Zhang G, Manaca MN, McNamara-Smith M, Mayor A, Nhabomba A, Berthoud TK, Khoo SK, Wiertsema S, Aguilar R, Barbosa A and others. (2012). Interleukin10 (IL-10) polymorphisms are associated with IL-10 production and clinical malaria in young children. Infection and immunity, 80:2316-22.

Zhao N, Chen HL, Chen ZZ, Li J, Chen ZB. (2017). IL-10-592 polymorphism is associated with IL-10 expression and severity of enterovirus 71 infection in chinese children. Journal of clinical virology: the official publication of the Pan American Society for Clinical Virology, 95:42-46.

Zimmermann P, Curtis N. (2020). Coronavirus Infections in Children Including COVID-19: An Overview of the Epidemiology, Clinical Features, Diagnosis, Treatment and Prevention Options in Children. The Pediatric infectious disease journal, 39:355368.

https://www.natureasia.com/en/nindia/artic le/10.1038/nindia.2008.254. More immunity genes in Indians. Nature India. doi:10.1038/nindia. 2008. 254. (Published online 1 August 2008). 